This article was downloaded by: [University of Michigan]

On: 11 November 2009

Access details: Access Details: [subscription number 908312433]

Publisher Routledge

Informa Ltd Registered in England and Wales Registered Number: 1072954 Registered office: Mortimer House, 3741 Mortimer Street, London W1T 3JH, UK

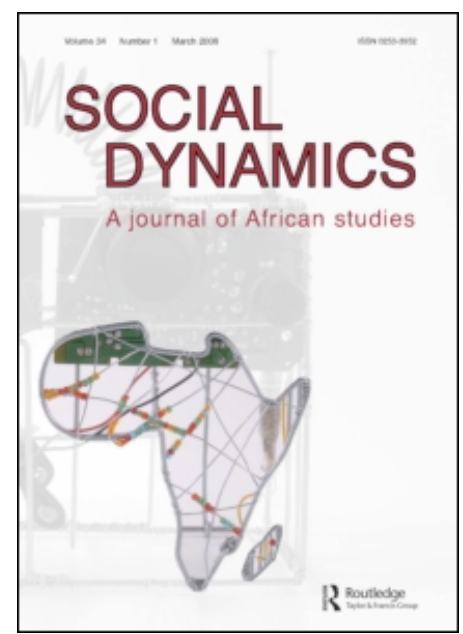

\title{
Social Dynamics
}

Publication details, including instructions for authors and subscription information:

http://www.informaworld.com/smpp/title content=t791476125

\section{Ambiguities of 'Culture' and the Antiretroviral Rollout in South Africa}

Adam Ashforth a; Nicoli Nattrass bed

a School of Social Science, Institute for Advanced Study, Princeton ${ }^{\mathrm{b}}$ School of Economics at the

University of Cape Town (UCT), ${ }^{\mathrm{c}}$ AIDS and Societ y Research Unit (ASRU), ${ }^{\mathrm{d}}$ Centre for Social Science

Research (CSSR) at UCT,

To cite this Article Ashforth, Adam and Nattrass, Nicoli'Ambiguities of 'Culture' and the Antiretroviral Rollout in South Africa', Social Dynamics, 31: 2, $285-303$

To link to this Article: DOI: $10.1080 / 02533950508628716$

URL: http://dx.doi.org/10.1080/02533950508628716

\section{PLEASE SCROLL DOWN FOR ARTICLE}

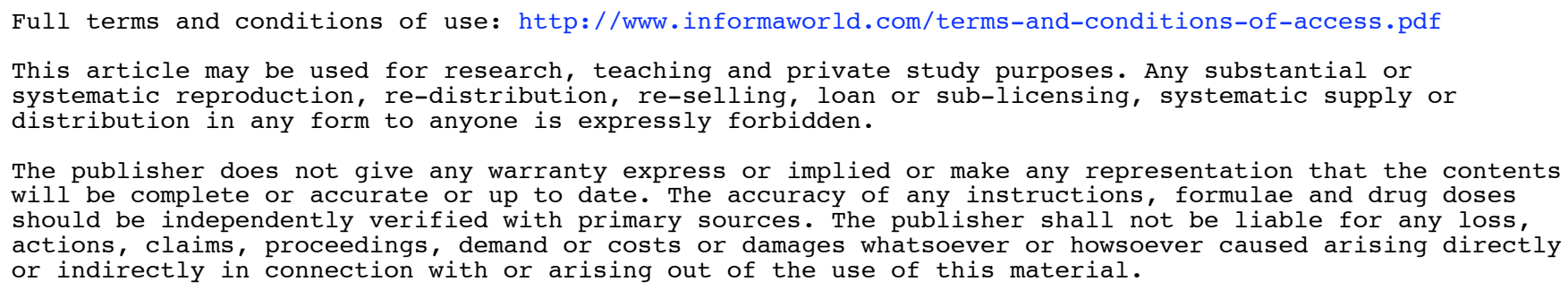

The publisher does not give any warranty express or implied or make any representation that the contents will be complete or accurate or up to date. The accuracy of any instructions, formulae and drug doses should be independently verified with primary sources. The publisher shall not be liable for any loss, actions, claims, proceedings, demand or costs or damages whatsoever or howsoever caused arising directly or indirectly in connection with or arising out of the use of this material. 


\title{
Ambiguities of 'Culture' and the Antiretroviral Rollout in South Africa
}

\author{
Adam Ashforth and Nicoli Nattrass
}

\begin{abstract}
This paper reflects on two contrasting cultural strategies for supporting the rollout of highly active antiretroviral therapy (HAART): The Treatment Action Campaign's Treatment Literacy Programme which seeks to educate people into a conventional scientific understanding of HIV disease and treatment; and a Department of Health Voluntary Counselling and Testing (VCT) video which harnesses putative 'indigenous knowledge' relating to illness and healing. It points out that the latter strategy risks connecting with fears regarding the 'African science' of witchcraft. This can serve to confuse, rather than clarify, ambiguities concerning the notion of 'cure'. Science education is challenging, but has the potential to empower patients to manage their illness effectively.
\end{abstract}

\section{Introduction}

A central issue for South Africa's rollout of highly active antiretroviral therapy (HAART) is how to signify the concepts of the virus, the immune system, and antiretroviral drugs for people with only limited education and limited exposure to bio-medical theories of disease. Two contrasting strategies are emerging for promoting adherence to HAART: one strives to educate HAART patients about the conventional scientific understanding of their disease; and the other attempts to harness putative 'indigenous knowledge' relating to illness and healing. This paper reflects on these different strategies as employed by the Treatment Action Campaign (TAC) and in a (VCT) video circulated by the Department of Health and widely used in public clinics. ${ }^{1}$ 


\section{'Body Soldiers,' Snakes, and the Concept of the 'Antiretroviral'}

In discussions with VCT counsellor employed in northern KwaZulu-Natal, two everyday metaphors were found to dominate understandings of the disease that clients brought to counsellors and which counsellors found themselves having to accommodate when describing HAART. The first invokes the metaphor of dirt and describes the infection as a form of pollution: 'dirty blood.' Many illnesses and everyday maladies in this part of the world are understood as resulting from pollution. Procedures of cleansing - particularly using purgatives and emetics - are staples of non-medical healers of all varieties. Some of these forms of pollution derive from breach of moral codes of 'taboos,' others are the result of more mundane encounters with filth (Ashforth, 2005a: 154-69). HIV, then, can be presented as another form of dirt in the blood and HAART as a cleaning agent.

The second metaphor frames the infection in terms of warfare. In this account, the body is being attacked by destructive forces which kill its 'soldiers' - amasojha omzimba, in Zulu. VCT counsellors in the Hlabisa District with whom I (Adam Ashforth) have discussed this issue are adamant that this concept of 'body soldiers' is an ancient Zulu notion. It cannot be found, however, in the work of ethnographers of Zulu medicine such as Bryant (1970), Conco (1972) and Ngubane (1977). It is, most likely, a Zulu translation of the concept of immunity. 'Amasojha' is, after all, a phonetic rendition in Zulu of the English word 'soldiers.'

The metaphor of 'body soldiers' has been dramatised in a video entitled Adherence to Anti-Retroviral (ARV) Therapy: A Life Choice which is widely used in preparing patients for admission to their ART programme. The video was written and produced by a Yale Medical School student, Ilene Yi-Zhen Wong, for a doctoral dissertation project and is now being distributed by the Department of Health, dubbed into local languages from its original English version, as a standard teaching aid for HAART clinics around the country. The script explains immunity, HIV, and antiretrovirals (ARVs) thus:

As you may know, your body's immune system - or amaso tsha amzimba (sic) is an army of soldier cells that guard your body from sicknesses like HIV. But HIV is a particularly bad sickness because it not only fights your body, it fights CD4 soldier cells. HIV is like a poisonous snake, sneaking up to the CD4 soldiers while they are sleeping and killing them. These snakes are small and wily, hiding, so the soldiers cannot find them to fight them. The snakes also 
breed very quickly, multiplying and multiplying until they overwhelm the CD4 soldiers and the body becomes very sick.

This is where ARVs come in. ARVs can prevent the multiplication of the HIV virus. It is as if the body's soldiers could find the HIV snake nests, and pour poison on the snake eggs to keep the eggs from hatching.

However, ARVs are a kind (sic) poison that only works for a limited amount of time. They must be taken every day, in the morning and evening, or else the HIV virus can start reproducing (Wong, 2004: 59).

In her thesis describing the video project, Wong hypothesised that a 'culturally-sensitive audio-visual patient education program may be of significant use in increasing patient understanding of concepts of resistance and medication taking skills, particularly in areas of low literacy' (ibid: 2). Her project demonstrated that ART patients were better able to answer questions about adherence to therapy after viewing the video, though she was unable to address its impact on adherence over the longer term.

Wong reports that patients watching the video were particularly responsive to the dramatisation, using tame snakes rented from a Johannesburg company called ReptiPet (ibid: 19), of attacks by snakes on body soldiers:

The wisdom of using a snake-soldier metaphor to describe the replication of the HIV virus was illuminated when one of the pharmacist viewers noted, 'It was very smart of you to use the snakes; Africans do not like snakes.' Indeed, the cultural significance of snakes clearly made a visceral impact on many of the patient viewers, grabbing their interest and giving the abstract concept of an unseen virus a concrete manifestation that could be 'fought against' by the 'soldiers of the body' (immune system)' (ibid: 40).

Wong does not discuss the origin of the snake-egg metaphor other than to report that her script 'was produced by the study author in conjunction with an experienced scriptwriter' and submitted for review to a focus group consisting of VCT counsellors who 'were specifically asked to comment on the appropriateness of the snake-egg metaphor' (ibid:18). These same counsellors were also asked 'what kind of animals were considered to be particularly frightening in their culture' and 'mentioned snakes as a potentially strong metaphor for Africans' (ibid: 26). The counsellors also told her that 'they frequently depict the HIV virus as a kind of monster' in their counselling work.

The use of snakes in an adherence education video may well prove effective. And the snake most certainly is a heavily-laden symbol in this part of the world. But there is more to its 'cultural significance' than Wong seems to have been aware of, for there are different types of snake and different 
cultural traditions pertaining to them in this part of the world. Pythons, for example, according to Axel-Ivar Berglund in his account of Zulu 'thought patterns and symbolism' 'symbolize togetherness, undivided oneness' and their skins are used in creating the inkhatha yesizwe the central symbol of Zulu national unity (Berglund, 1976: 61). Berglund, following the work of A.T. Bryant, spent a great deal of time discussing the symbolism of snakes with Zulu informants in the 1960 s who insisted that a wide variety of snakes could be the manifestation of ancestral spirits, or 'shades,' charged with protecting the welfare of their descendants. These shade snakes are also associated symbolically with childbirth and the transfer of the spirit of shades to newborns. In the words of one informant, a diviner,

The child grows for nine months (lit. moons). It is born in the tenth. The shades drive it out from the womb. It glides out, leaving behind its skin (placenta). All this is like the snake that leaves its skin. It (the snake) is like the child when it comes out of the womb. The snake discards the skin as the child discards the placenta (Berglund, 1976: 96).

This same diviner also explained how he used the skin of a snake in treating difficulties relating to childbirth (ibid: 97). Snakes are also, according to Edward Green, taken by many in southern Africa to symbolise the source of bodily power and purity (Green, 1996). Snakes, particularly pythons, are often associated with the experience of the 'call' to become a diviner and many healers report spending time beneath water in a river or a lake communing with a snake. Zulu diviners use the vertebrae of dangerous snakes caught during their initiation to demonstrate their courage and the power of the ancestral spirits to protect them (Berglund, 1976: 156).

Different peoples have different traditions relating to snakes. Nowhere is this better described than in A.C. Jordan's classic Xhosa-language novel, The Wrath of the Ancestors, where a young Mpondomise royal marries a girl from another nation whom he meets at Fort Hare University. When the young bride notices a snake near her newborn baby, she panics and kills it, much to the horror of her husband's people who attribute the snake to a manifestation of the ancestors and subsequently lay the blame for great misfortunes befalling the nation upon the heedless bride (Jordan, 1980). In addition to real snakes being interpreted as representations of ancestral spirits, a variety of what might be called mythical snakes populate the south of Africa. Amongst these the best known are the snakes Mamlambo - a voracious creature with whom a person enters a sort of devil's compact by sacrificing blood kin in return for power and wealth (See Hunter, 1961: 287); 
and iNkosi ya Manzi, a giant snake that lives in water and wreaks destruction in the form of tornadoes (see Ashforth, 1998).

Perhaps the strongest image associated with snakes in these parts, however, is that of witchcraft. The snake serves in two distinct guises when it comes to witchcraft: as an emissary or 'familiar' dispatched by a witch in order to cause harm and misfortune and as a creature manufactured by a witch and dispatched in muthi which, when eaten with food (either in a real meal or food taken in a dream), consumes the victim from within (see Ashforth 2005a, 2005b). This form of witchcraft is known, in Zulu, as idliso. Idliso and the ailments associated with it are usually translated into English as 'poison' and 'poisoning,' but the understandings of the power of substances to cause harm that are typically engaged in notions of idliso/sejeso and the substances that serve as the medium of engagement between the witch and his or her victim are much broader than the concepts of 'poison' that inform biomedical notions of infection or basic principles of toxicology. The witch deploying muthi in the manner of idliso manufactures a creature that manifests itself in the body of the victim in a form resembling a snake, lizard, or crab and devours the victim from within, causing all manner of misfortune to befall the person in the process. ${ }^{2}$ When referring to poison in English, however, Africans with a vivid sense of the powers of muthi invoke a much wider field of action and intention in relation to the agency of substances than that typically imagined by toxicology (Ashforth, 2005b). A video embracing both the image of the snake and the idiom of poisoning is entering a cultural zone where interpretations of meaning cannot easily be predicted.

Symptoms of illness associated with the onset of AIDS, such as persistent coughing, diarrhea, abdominal pains, and wasting, have long been associated with the malicious assaults of witches (see also Henderson, 2005). Preliminary analysis of the verbal autopsy narratives in the Africa Centre's Demographic Information System found that one in four deaths identified by physicians as AIDS-related are identified by informants as being caused by ubuthakathi, or 'witchcraft' (a concept incorporating both the inherent capacities of human persons to cause supernatural harm and their use of substances in sorcery to do so). This is a surprising result, not so much for the extent of the belief in witchcraft - a wealth of anthropological literature over the past two decades (Moore and Sanders, 2001), suggests this is an underrepresentation of the actual prevalence of witchcraft beliefs - but rather for the fact that people are prepared to speak openly to a stranger about matters that are highly sensitive in family and community relations (Ashforth, 2005a: 
Ch.3). For when an illness or death is said to be caused by witchcraft, it is interpreted by kin and others connected with the deceased as having been deliberately inflicted by others within the victim's community. That is to say, such a death is akin to murder - only the forms of violence are believed to be occult (Ashforth, 2001). The most common form of witchcraft cited in the verbal autopsy reports is idliso.

Other ways of using muthi are also said to kill in a manner similar to AIDS. AIDS-awareness accounts of HIV as an invisible agency inhering in the already potentially dangerous mess of bodily fluids that is the medium of exchange of sex resonate powerfully with local understandings of invisible agents involved in witchcraft that contaminate a victim and then begin to 'attack' the victim by destroying the person's defenses, precipitating illness, misfortune, and death. The language of 'attack' and 'defense' common in virology and AIDS-awareness discourses is precisely the same language used in describing the actions of poison and poisoners spoken of as 'witcheraft.'

The soldier-snake metaphors and the idiom of medicine as poison in the ARV adherence video, then, while striking the medical student Ilene Wong as 'culturally appropriate' gloss over a host of questions of agency emerging from the context of the epidemic, questions such as: What kind of snakes are these? Who sent them? Are they merely 'natural' or do they embody some sort of supernatural power or answer to the direction of some other person or being? How do procedures devised to protect against other sorts of dangers posed by snakes relate to ARVs and their mode of poisoning snake eggs? How do the powers embodied in ARVs relate to and compare with those inherent in the muthi used by traditional healers or the healing substances used by faith healers?

Even for those who have not been exposed to the soldier-snake video, questions of agency remain pressing. The point here, is not that the video is necessarily misguided, but rather that a widespread process of cultural change is underway in South Africa driven by the biological forces of the epidemic, the medical imperatives of securing treatment, the particularities of local schemes of interpretation, and struggles amongst local, national, and global authorities producing definitive interpretations. The politics of a person's relations with the invisible forces he or she experiences as acting upon the course of life are not always easy to predict. 


\section{Ambiguities of Treatment}

One of the problems involved in harnessing metaphors from putative 'indigenous knowledge' about illness and healing in the pursuit of good adherence to HAART is that they risk connecting with fears regarding the 'African science' of witcheraft (Ashforth, 2005a; 2005b). This can serve to confuse, rather than clarify, ambiguities concerning the notion of 'cure'.

The first ambiguity involves the description of ARVs as involving 'poison'. This is likely to resonate powerfully with the discourse employed by the Health Minister when she describes ARVs as 'poisonous' (for example, Cullinan, 2005). The obvious question then, is poisonous for what? Are antiretrovirals poisonous for the virus eggs (and hence good for the person) or are they poisonous to the person also (as implied by the Health Minister's description of HAART as toxic)? Or both? Moreover, in local understandings of 'muthi' as both medicine and poison, the active agency in the substance (whether it be used to heal or harm) is subject to direct manipulation by the person deploying it (whether healer or witch). What are the possibilities of willful manipulation of the 'poison' in ARVs by the patient or others?

AIDS denialists in South Africa blame the symptoms of AIDS on malnutrition and on the 'poisonous' effects of antiretrovirals themselves - the implication being that HAART is more harmful to the person than the disease. As Brink puts it, employing another war-based metaphor, using antiretrovirals is like 'napalm-bombing a school to get rid of some roof rats' (Brink, 1999). They also frequently speak of a conspiracy by multinational pharmaceutical companies foisting this 'poison' on innocent Africans.

The second ambiguity arises from the transformation by HAART of AIDS from a 'death sentence' to a 'manageable chronic condition.' Local understandings of illness caused by witchcraft resonate well with notions that a person's health can be restored through a never-ending battle against a disease, which although beaten back, remains a perpetual threat to the individual and to others. This is why witches are killed and why traditional healers typically promise that their treatments for bewitchment will return the evil forces responsible to the person who dispatched them, killing the witch in the process. The notion of a disease being 'incurable' before the struggle has even begun, despite perhaps being 'manageable,' is historically unknown to traditional healing. 
HAART occupies a distinctly ambiguous position within that body of shared representations in which illness is depicted as a struggle between forces responsible for health and well-being and evil forces bent on causing suffering, misfortune and death. Within this political and moralised conception of illness and healing, the notion of an 'incurable' or terminal disease presents categorical difficulties. For to name an illness as 'incurable' in advance of the struggle to restore health and wholeness is implicitly to deny the power of healers, medicines, ancestors, spirits and, ultimately, God, to preserve life. It is thus a threat to the reputation of the healer, if not blasphemy.

\section{Implications for Stigma}

To name a disease as incurable is tantamount to saying a person is already dead and thus to raise questions about the dangers of pollution that person may present to others with whom they come into contact - questions which neither 'tradition' nor 'science' is currently able to answer. A person accustomed to local rituals and practices relating to death coming into contact with an AIDS victim may understand well that they have a minimal risk of catching HIV from that person, since they know HIV is a virus transmitted through sex, yet still fear the presence of this person for the same reasons they might fear the presence of the already dead. If they believe that people named as carrying AIDS will soon be dead, they might worry about whether contact with them risks exposure to those unknown and indefinable forms of pollution that may, perhaps, bring misfortune in a manner similar to that of the wellknown pollution emanating from those already dead (Ashforth, 2005). The point here is not that there are 'African traditions' teaching 'culture' about these things. On the contrary, in the absence of authoritative traditions and respected authorities prepared to address the sources of their fears, people are forced to figure out the new dangers for themselves. Clearly one of the things they have figured out is that being in contact with people dying of AIDS is a dangerous matter.

This suggests that the relationship between HAART and the reduction of stigma is probably a lot more complex than hoped for by treatment activists such as Paul Farmer who argue that HAART will reduce stigma simply by virtue of it being a form of 'treatment' (see Arachu and Farmer 2005). Insofar, and for so long, as treatment is successful the patient will seem healthy and the risk of pollution to others from contact with those 'already 
dead' will diminish along with the 'stigma' related to this. When, however, treatment fails (once patients develop resistance to the two lines of therapy currently on offer in the public sector), then the question of pollution will arise again. As shown in Figure 1, the ASSA2003 demographic model estimates that the numbers of people on HAART will rise to over 1.2 million by 2015 . However, by that time, there will still be almost half a million people AIDS sick and without access to HAART, and a further 143,000 people who have become AIDS sick once again as a result of treatment failure.

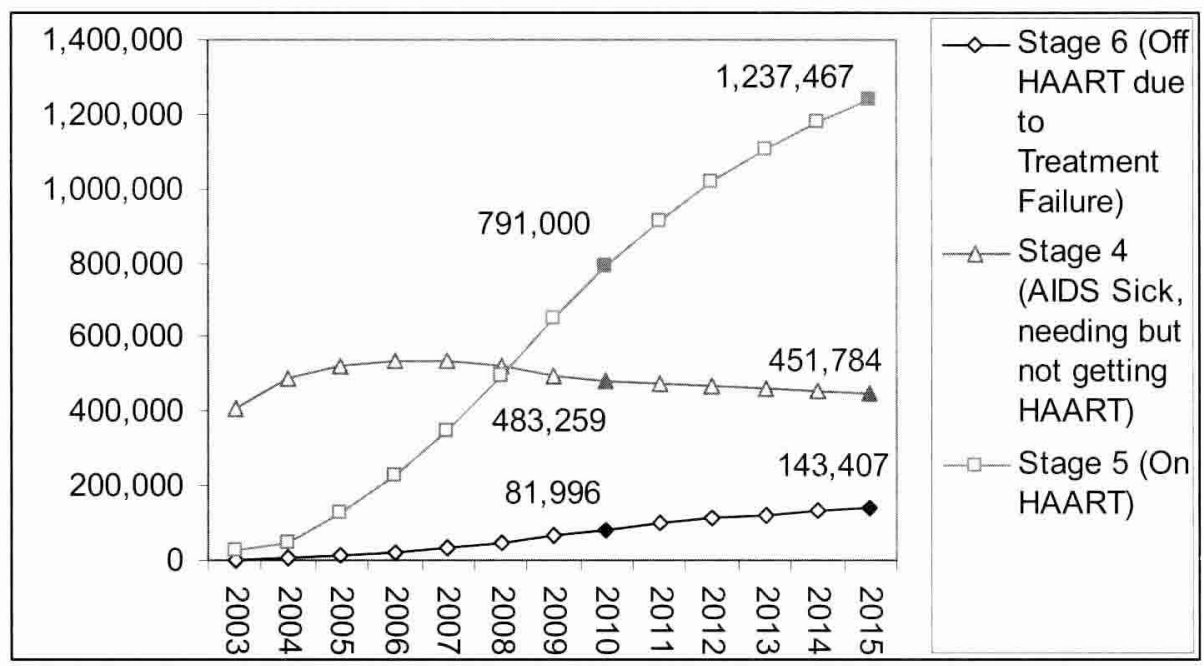

FIGURE 1: Projected Numbers of People on HAART, Needing HAART, and Resistant to HAART

Source: ASSA2003 Demographic Model.

Of course if HAART regimes turn out to be widely successful and reduce the perceptions of AIDS as being an incurable disease, AIDS-related stigma may decline and persons living with AIDS become no more remarkable than those with diabetes or hypertension. Such an outcome, however, would further complicate prevention campaigns and safe-sex messaging.

There have been attempts to reduce stigma towards HIV-infected people as part of an HIV/AIDS education campaign involving the public disclosure of HIV status of activists. This was at the heart of the GIPA (greater involvement of people with AIDS) principle embedded in many African AIDS interventions (Nguyen, 2005). This resulted in a proliferation of 
workshops involving 'confessional techniques' often taking an 'evangelical form' in which people were trained to talk about HIV and to teach other about treatment possibilities (ibid). The very notion of a 'confession' is linked to ideas of redemption - such as when people confess to witchcraft as an attempt to cleanse themselves of it (Ashforth, 2005) and hence may possibly have some purchase in addressing stigma.

According to Robbins (2006), public accounts by TAC activists about how HAART saved them from 'near death', restoring them to 'new life' can be understood as a form of ritual which facilitates activist commitment and grassroots mobilisation. However, such public 'confessions'/disclosure have their own costs and ambiguities. Almeleh (2005) has shown that so-called 'public' disclosure is very context-bound and that activists disclosing in public at AIDS events are not necessarily doing so in their own communities. Furthermore, there are reports that Southern African audiences at AIDS awareness events do not always believe the 'confessor' - seeing them as paid 'actors', especially if the same people appear also in documentary films (Levine, 2005). Kalofonos (2005) notes that in Mozambique, disclosure-based initiatives are closely linked with Pentecostal Churches, which emphasise confession as an integral part of the exorcism of demons, and that the associated workshops are infused with 'new age' inspired 'talk to the virus' exercises.

AIDS and the HAART rollout are clearly having, and are going to continue to have, a major impact on cultural understandings and representations of disease. This is because people get better on HAART - and dramatically so. This, in and of itself, will have a transformative social impact. As Nelis Grobbelaar (a Western Cape based AIDS physician) points out, he stays in ARV medicine because of the 'magic' of the social response to HAART:

You give a really sick man ARVs, he is a mess, you think it won't work, then three months later, he is back, he is well, he has brought other family members to the clinic. They don't need counselling because they have already all been counselled by that man. This is the 'magic' which keeps me going. We need to generate more of it through the rollout. (Comment during a round table discussion at the Symposium on AIDS and Citizenship in Southern Africa, Gordon's Bay, December 2005).

Strategies designed to harness local images of illness must be sensitive to such transformative dynamics being unleashed every day through therapeutic relationships between doctors and HAART patients. They must also be able to respond flexibly to how new representations and 
understandings of HIV illness are being taken up by healers operating outside of conventional biomedicine. As noted above, healers are in a deeply compromised position when it comes to a disease being defined at the outset as 'incurable' - as it renders their healing strategies as hopeless from the start.

The HAART rollout, however, presents new ways of framing the issue. Healers could, for example, excuse themselves for failing to cure the disease by saying that AIDS is a 'new' disease for which the ancestors have no cure. There is some evidence of healers doing precisely this (see Wreford, 2005; Henderson, 2005; Mills, 2005). Such a strategy provides the healers with the discursive space to recommend that the patient attends an AIDS clinic to get more soldiers for the body (Henderson, 2005). They may add to this recommendation by suggesting that such biomedical treatment will not be effective if the continual onslaught of misfortune is not simultaneously dealt with by services offered by the healer. This kind of simultaneous involvement of HAART patients in both forms of 'healing' is probably the best outcome possible for those seeking collaborative arrangements between 'traditional' and Western biomedicine.

However, some (if not most) healers may reject this narrative entirely, and stick with the African science paradigm of bewitchment and cure. Many people with AIDS would prefer to be 'cured' - or at least be represented as 'cured'. For this reason, healers peddling AIDS cures are not likely to want for customers, even if their customers die as a consequence. Death can always be depicted as resulting from the initial witchcraft, or as a consequence of the customer being called by God.

\section{TAC's Treatment Literacy Project as a Cultural Project of Science}

The 'African science' of witchcraft and healing rests on a different set of propositions about illness and healing to conventional science (Ashforth, 2005a, 2005b). This poses a problem for the TAC which, as argued below, promotes a scientific world-view, but wishes also to communicate effectively with its membership - many of whom may choose to use traditional remedies as well. Thus far, the TAC has adopted a sympathetic and inclusive position towards traditional healers - but has done so explicitly within a paradigm that privileges science. For example, the TAC fact sheet 'Talk about Antiretrovirals' includes a question and answer for Prudence Mabele, a 
traditional healer. In addressing the question whether a person on ARVs can take traditional remedies, Mabele answers as follows:

I am a traditional healer. I believe in traditional remedies but I also take ARVs. Traditional remedies are chemicals, just like medicines. Some of them can have negative effects if combined with ARVs. This is called drug interaction. We don't know how some traditional medicines affect the immune systems of people with HIV. If you take traditional medicines, tell your doctor, especially if you take ARVs. Make sure your traditional healer knows about HIV and how ARVs work.

The quote makes it clear that 'your doctor' is the key person to listen to, and that alternative remedies should probably be avoided because of drug interactions. Although it does not go quite as far as rejecting traditional healing as a treatment strategy, the TAC literature confronts the issue of an incurable disease head-on by comparing it to other, commonly experienced and understood medical conditions like high blood pressure:

It is true that many people die of HIV-related illnesses, but an HIV-positive person can live a long and healthy life. The public perception that 'there is no cure for HIV' is confusing. It is true that, at the moment, there is no cure for HIV. However, there is also no cure for potentially deadly chronic illnesses such as sugar diabetes or high blood pressure. Nevertheless, people who have these illnesses can live normal lives provided they stay on treatment. This is also the case with HIV, especially if you look after your health, treat any infection you get early, and get antiretroviral treatment for HIV (TAC, 1999: 4).

This approach is a straight endorsement of conventional science, and of conventional health practitioners. The advice given by TAC is to come to terms with HIV infection, join support groups, learn about the biology of the disease and forge an informed relationship with your doctor. Rather than trying to manipulate local understandings, TAC's strategy has been one of education and profound cultural transformation in favour of biomedical understandings of HIV and HAART.

\section{The TAC Treatment Literacy Project}

The TAC's Treatment Literacy Programme is designed to teach people the science of HIV and of antiretroviral treatment in order to promote good adherence and to empower patients in their dealings with doctors (2006: 3-6). TAC produces fact sheets and posters about HIV disease, antiretroviral treatment and CD4 count monitoring. ${ }^{3}$ These are distributed at workshops around the country run by treatment literacy practitioners. The TAC treatment literacy project entails a hierarchy with the national treatment literacy co- 
ordinator (Nomfundo Eland) at the head, provincial treatment literacy coordinators beneath her, TAC treatment literacy trainers beneath them and then TAC treatment literacy practitioners at grass roots level. Although in theory the treatment literacy practitioners are supposed to run workshops with the general public and TAC branch members, in practice the entire hierarchy is often involved in workshops (Nathan Geffen, personal communication).

There is a strong emphasis in the workshops on using the language of medical science. TAC's own fact sheets use it, and additional materials used by TAC (such as the 'Body Visual' and accompanying manuals developed by the AIDS and Society Research Unit at the University of Cape Town) similarly adopt a scientific approach. The human body is represented simply, but accurately. People at TAC workshops are shown how to understand their illness and the way ARVs work by giving them the tools of medical science. This approach stands in sharp contrast to that of the VCT video used by the Africa Centre. As Nathan Geffen, TAC's Research Office, comments, TAC's focus on science is the reason:

why many of our members are able to explain, for example, what a Nucleoside Reverse Transcriptase Inhibitor is (and some of us will draw pictures to prove it too). Try doing that with snakes and soldiers! It is a patronising, racist, Verwoedian attitude to presume black people can't learn science. If teaching HIV using the language of science couldn't work or wasn't working, then by all means use snakes and soldiers if it saves lives. But we, ARK, MSF [non governmental organisations involved in the HAART rollout] and others have all demonstrated that it does work (email communication, April 2006).

Rather than appealing to putative local understandings and imagery, the TAC is engaged in a broader project that attempts to alter, through science education, the cultural perspectives of HAART patients towards their illness and healing strategies. And, by training people in the language of science, TAC is assisting HAART patients to understand the nature of various monitoring tests, and empowers them to engage with their doctors over sideeffects and treatment regimens. For example, the TAC fact sheet 'What is a CD4 count?' explains that HIV attacks CD4 cells (which are part of the immune system) and teaches people how to read and understand the results of a CD4 test. CD4 tests are important for keeping track of the progression of HIV disease and for indicating if HAART is becoming less effective through the development of resistance. Explaining the significance and meaning of a CD4 test is thus empowering of patients in ways that the snake-soldier imagery could never be. 
In March 2006, TAC produced an issue of their magazine, Equal Treatment dedicated to the science of AIDS. It has well informed articles on 'how we know that HIV causes AIDS' (Geffen, 2006), 'how HIV works' (including several scientific diagrams explaining how HIV replicates in a cell) (Sonenthal, 2006), 'how we know HIV tests are accurate' (Manchanda and Sayana, 2006a) and 'how we know that antiretrovirals save lives' (Manchanda and Sayana, 2006b). The section on the science of AIDS concludes with a page listing the key scientific articles and resources that informed the simple (but accurate) articles in the issue. As is clear from the editorial of this issue of Equal Treatment (Mthathi, 2006), obtaining an understanding of the value of science and of the science of AIDS and antiretroviral treatment is a key concern for the TAC leadership:

Science enables us to know many things with confidence. With regard to HIV, we know that it causes AIDS, antiretrovirals save lives, condoms prevent infection and nutrition is important to maintain health. This month's cover is a three-dimensional image of HIV. It was published in January in a scientific journal called Structure... Technology enables us today to take photos of something so small: 1,000 viruses in a line are the breadth of a human hair!

But in many communities we work with, disease is not understood to be the result of a germ. An old woman in Qumbu said we must cover our noses, because 'AIDS comes from the wind, like TB. Your enemies can send this thing to you'. To this woman, the front cover would look like a drawing by an artist, not the virus that brings so much illness to our communities

TAC's treatment literacy programme works to demystify science. Join our community activists in discovering the common sense of science

The contrast between Ilene Wong's VCT video's snake imagery (which resonates with understandings of illness as caused by the maleovalence of others) and Mthathi's call for people to understand the science - and not be like the 'old woman in Qumbu' who thinks that AIDS can be sent by enemies - could not be more striking.

TAC is effectively engaged in a major cultural project that involves changing the way that people see things. As is evidenced by the articles in Equal Treatment starting with the words 'How we know that...', the science is not presented as a rival alternative world view that people should just convert to, but is presented as a form of thinking. Care is taken to summarise different studies, and to lead the reader to an understanding of how these studies support the broader science of AIDS. The objective is not only to empower HAART patients by explaining to them how HAART works, but it also assists TAC members to counter the arguments put forward by AIDS denialists, such as those linked to the Rath Foundation that peddles vitamins 
as an alternative to HAART (see Geffen, 2005). For example, Machanda and Sayana (2006b: 8) present the results of a 2006 American trial as follows:

A trial by the US National Institutes for Health found that people who take antiretroviral treatment continuously are half as likely to develop AIDS or die as people who take structured treatment breaks in their treatment. This finding on its own refutes the AIDS denialists. If antiretrovirals are bad for you, as the denialists claim, then why do people who take them continuously do better than people who only take them sometimes.

The TAC fact sheet 'Talk about Antiretrovirals' presents common questions and answers. The answers are attributed to real people with names and photographs. In this sense, the strategy parallels public disclosure by HIV activists as a form of consciousness raising. Thus, for example, Nontsikelelo Zwedala answers the question 'How do ARVs work?' with the following:

They reduce the amount of virus in my blood. This helps my immune system to work properly again and to fight off infections that make people with HIV sick. I weighed $42 \mathrm{~kg}$ when I started ARVs. I was close to death. Now I weigh over $60 \mathrm{~kg}$ and am working and healthy. To meet the challenges of HIV, we must take responsibility to learn about the disease and become treatment-literate. It is not only our doctors and nurses who must understand our medical needs. We must understand them too.

According to Robbins, an anthropologist who witnessed a few treatment testimonies (like the one above) at a TAC national conference, such testimonies 'with their references to CD4 counts, viral loads and the role of TAC in giving 'new life' - seem to blur the lines between science and religion, medicine and spirituality, and technology and magic' (2006 forthcoming). Whilst they could be 'read' as indicating a spiritual and magical approach on the part of the testifier (as assumed by Robbins), they could equally well (and more appropriately) be taken at face value as testimonies to the power of science to combat AIDS. As argued above, TAC promotes scientific education so as to empower people in their search for healing. It would be surprising if those presenting treatment testimonies at a TAC national conference using scientific categories were not doing it from an informed perspective.

\section{Conclusion}

Not everyone, of course, is as trained as a TAC treatment literacy advocate, and probably not even all these activists have a good enough knowledge of science to educate others fully about the science of HIV and antiretroviral therapy. Furthermore, as Ashforth (2005a) has argued, escaping the world of 
witches is not always easy. Obtaining a scientific understanding of HIV does not necessarily purge the worry that possibly the disease was 'sent' by an enemy, and hence that the quest for healing should involve both African and conventional science. As Nana, the young woman discussed in Mills (2005) who had her health restored by HAART, explained, sometimes she does, and sometimes she does not believe in sangomas. People's search for healing is likely to be multi-faceted, with many adopting a trial and error approach. It is thus far from clear how this cultural struggle over HIV disease and appropriate forms of healing will turn out.

To add to the problem is the over-arching challenge by the state to the legitimacy of science itself (Geffen, 2005). This has added a third ingredient to the contest over healing strategies between 'African science' and biomedical science, that is, state-sponsored pseudo-science. Thus, not only does TAC have to educate people about the science of HIV, but they also have to explain the logic and necessity of double-blind clinical trials in order to dispute the Health Minister's support for purveyors of untested substances. Probably our best hope in these circumstances is that the HAART rollout will win its own converts by demonstrating its effectiveness on a wide scale, that is, that Dr Grobbelaar's social magic will prevail.

Adam Ashforth is a Visiting Associate Professor of Social Science at the School of Social Science, Institute for Advanced Study, Princeton. He is the author of Madumo, A Man Bewitched (Chicago: University of Chicago Press and Cape Town: David Philip, 2000) as well as Witchcraft, Violence, and Democracy in South Africa (Chicago and London: University of Chicago Press, 2005). His email address is Ashforth@ias.edu.

Nicoli Nattrass is professor in the School of Economics at the University of Cape Town (UCT) and director of the AIDS and Society Research Unit (ASRU) with in the Centre for Social Science Research (CSSR) at UCT. She is the author of The Moral Economy of AIDS in South Africa and has completed several other publications that analyse issues related to HIV/AIDS, including the disability grant tradeoff, access to antiretroviral treatment etc. See www.cssr.uct.ac.za for more details. She lectures the 'Economics of AIDS in Sub-Saharan Africa' master's level course, amongst others, at UCT. Her email address is nnattras@commerce.uct.ac.za. 


\section{References}

Almeleh, C. 2004. The Longlife AIDS Advocacy Intervention: An Exploration into Public Disclosure, Centre for Social Science Research Working Paper no. 96. Cape Town: University of Cape Town, available on www.cssr.uct.ac.za

Arachu, Castro and Paul Farmer. 2005. Understanding and Addressing AIDS-Related Stigma: From Anthropological Theory to Clinical Practice in Haiti. American Journal Public Health 95(1): 53-59.

Ashforth, Adam. 1998. Reflections on Spiritual Insecurity in a Modern African City (Soweto). African Studies Review 41(3): 36-67.

Ashforth, Adam. 2001. 'On Living in a World With Witches: Everyday Epistemology and Spiritual Insecurity in a Modern African City (Soweto).' Magical Interpretations: Material Realities. Eds. Henrietta Moore and Todd Sanders. London, Routledge.

Ashforth, Adam. 2005a. Witcheraft, Violence, and Democracy in South Africa. Chicago and London, The University of Chicago Press.

Ashforth, A. 2005b. Muthi, Medicine and Witchcraft: Regulating 'African Science' in PostApartheid South Africa? in Social Dynamics. 31(2): 211-42.

Berglund, Axel-Ivar. 1976. Zulu Thought-Patterns and Symbolism. Bloomington and Indianapolis, Indiana University Press.

Brink, A. 1999. AZT: A Medicine from Hell, in The Citizen, 17 March.

Bryant, A. T. 1970. Zulu Medicine and Medicine-Men. Cape Town, Struik.

Conco, W. Z. 1972. The African Bantu Traditional Practice of Medicine: Some Preliminary Observations. Social Science and Medicine, 6: 283-322.

Cullinan, K. (2005). Health Minister promotes nutritional alternatives to ARV rollout. Healthe news, 30/5/05, (available on www.health-e.org.za)

Farrand, Dorothy. 1980. An Analysis of Traditional Healing in Suburban Johannesburg. MA thesis, Department of Psychology, University of the Witwatersrand.

Geffen, N. 2006. How we know that HIV causes AIDS, in Equal Treatment, March 2006: 2-3

Green, E. C. 1996. Purity, Pollution and the Invisible Snake in Southern Africa. Medical Anthropology 17(1): 83-100.

Henderson, P. 2005. A gift without shortcomings: Healers Negotiating the Intersection of the Local and Global in the Context of HIV/AIDS. in Social Dynamics. 31(2): 24-55.

Hunter, Monica. 1961. Reaction to Conquest: Effects of Contact With Europeans on the Pondo of South Africa. Second. London, Oxford University Press (for the International African Institute).

Jordan, A. C. 1980. The Wrath of the Ancestors : A Novel. translated from the original Xhosa by author with the help of Priscilla P. Jordan. Cape Province, Lovedale Press. 
Kalofonos, I. 2005. 'Treating AIDS in Mozambique: Evangelism, ARVs and A Vida Positiva', presentation at the Symposium on AIDS and Citizenship in Southern Africa, Gordon's Bay, December.

Levine, S. 2005. The Trouble with Assuming Ignorance: Documentary Film and HIV/AIDS Intervention in Southern Africa, presentation at the Symposium on AIDS and Citizenship in Southern Africa, Gordon's Bay, December.

Manchanda, R., and S. Sayana. 2006a. 'How we know that HIV Tests are Accurate', in Equal Treatment, March: 6.

Manchanda, R., and S. Sayana. 2006b. 'How we know that antiretrovirals save lives',: in Equal Treatment, March 8-9

Mills, E. 2005. HIV Illness Meanings and Collaborative Healing Strategies in South Africa. In Social Dynamics. 31(2): 126-60.

Mtalane, L. J., L. R. Uys, and E. M. Preston-Whyte. 1993. The Experience of Terminal Illness Among Zulu Speaking Patients and Their Families. International Journal of Nursing Studies 30(2), 143-155.

Mthathi, S. 2006. Editorial, in Equal Treatment, March: 1.

Moore, Henrietta and Todd Sanders. 2001. 'Magical Interpretations and Material Realities: An Introduction.' Magical Interpretations, Material Realities: Modernity, Witchcraft and the Occult in Postcolonial Africa. Eds. Henrietta Moore and Todd Sanders. [1], 1-27. London and New York, Routledge.

Ngubane, Harriet. 1977. Body and Mind in Zulu Medicine: An Ethnography of Health and Disease in Nyuswa-Zulu Thought and Practice. London, Academic Press.

Nguyen, V.K. 2005. ARVs, Therapeutic Citizenship and President Bush's AIDS Program for Africa', presentation at the Symposium on AIDS and Citizenship in Southern Africa, Gordon's Bay, December.

Oosthuizen, Gerhardus C. 1992. The Healer-Prophet in Afro-Christian Churches. Leiden: E. J. Brill.

Robbins, S. 2006. 'Rights, passages from 'near death' to 'new life': AIDS activism and treatment testimonies in South Africa', in American Anthropologist, 108(2), June (forthcoming).

Sonenthal, P. 2006. How HIV Works, in Equal Treatment, March: 4-5.

TAC. 1999. HIV in Our Lives. Available on www.tac.org.za

TAC. 2006. ARVs in Our Lives. A Handbook for People living with HIV and Treatment Advocates in Support Groups, Clinics and Communities.

Wilkinson, D., L. Gcabashe, and M. Lurie. 1999. Traditional Healers as Tuberculosis Treatment Supervisors: Precedent and Potential. International Journal of Tuberculosis and Lung Disorders 3(9): 838-842. 
Wong, Ilene Yi-Zhen. The Development \& Assessment of an Innovative Video to Introduce Concepts of Adherence in Soweto, South Africa. 2004. Yale University School of Medicine.

Wreford, J. 2005. Missing each Other: Problems and Potentials for Collaborative Efforts between Biomedicine and Traditional Healers in South Africa in the Time of AIDS. In Social Dynamics. 31(2): 55-89

\section{Notes}

This paper draws on research in northern KwaZulu Natal conducted by Adam Ashforth while a Visiting Scientist at the Africa Centre for Health and Population Studies in 2004 and research on TAC by Nicoli Nattrass.

For a description of idliso in relation to biomedical interpretations of symptoms, see Conco (1972); for a psychological study of suffering from what was considered to be idliso, see Farrand (1980); and for accounts of traditional healers and AIC prophets comparing idliso with tuberculosis, see Wilkinson, Gcabashe, and Lurie (1999) and Oosthuizen (1992: 100) respectively.

Much of this material is on the TAC website (www.tac.org.za). 